\section{Industry structure and innovation in the U.K. defense sector}

\section{Peter Hall and Andrew James}

$\mathrm{I}$

the United Kingdom, as elsewhere, the defense industry has undergone substantial structural change since the end of the Cold War. This is reflected in consolidation at the overall sector level, although with wide variations among subsectors in the potential for competition. While the nature and strength of causal connections remains a subject of debate, economic theory suggests that such consolidation might be expected to have implications for industry innovation. In this article, we observe that the defense industry's own-funded research and development (R\&D), a key metric for innovation, fell sharply as a proportion of total defense industry R\&D between 1989 and 2005. Statistics available in the public domain constrain exhaustive analysis of the connections, if any, between structural change in the sector and innovation, but we draw on recent advances in the theoretical debate to argue that observed changes are consistent with a nonlinear (inverted U-shape) relationship. ${ }^{1}$ We suggest that Ministry of Defence (MoD) policies may also have played a role, and that innovation may have fed back into structural change.

\section{The changing structure of the U.K. defense industry}

The notion of "defense industry" is ambiguous for reasons that are well known. Inputs ultimately used to form military capability, for example, are also used in the nondefense economy and produced by firms that predominantly serve civil markets. Many firms that could, in principle, produce for defense, and may in the past have done so, do not currently sell to the military and do not seek to. And if one considers the defense industry of a specific country, confounding issues surround the nationality of firms' ownership and the location of production to meet the demands of the domestic defense purchaser. Which firms may therefore be said to comprise the defense industry, generally and in specific nations, ultimately becomes a matter of judgment. In this study, we focus on firms which were awarded prime contracts by the U.K.'s MoD. Some of these firms were foreign-owned, a matter taken up again below. Some component manufacture and production work to meet contractual obligations has undoubtedly been performed offshore (and may well have increased) but information on the public record is insufficient to allow us to quantify the proportions involved.

Our analysis of change is based on observations of the firms in receipt of major contract awards first in 1990/1 and then in 2005/6. We note first that the number of companies undertaking the largest defense contracts shrank during our period of study. At the level of the largest contracts (over $£ 375$ million in 1990/1 and over £500 million in 2005/6), five firms were at work at the start of the 1990s but by the mid-2000s, the number had dropped to four. In relation to the next lower-valued range of contracts, £151-375 million (1990/1) and $£ 250-£ 500$ (2005/6), the number of firms fell from 11 to $9 .^{2}$ Second, membership of the lists of prime contractors changed substantially. Of the total of 16 firms in the two contract-value brackets in 1990/1, only four remained among the 13 in

the corresponding groups in 2005/6. British Aerospace had merged with GEC Marconi to form BAE Systems, by 2005/6 the single largest business in the U.K. industry, and Babcock International and Rolls Royce were also still players. Among firms to disappear from the list of largest prime contractors were VSEL and while a number of medium-sized contractors (e.g., Racal, Ferranti, and Alvis) also exited. Third, the supplier base became more international as U.S., Italian, French, and European transnational companies entered the U.K. industry to replace the mostly local firms that departed. New overseas players undertaking contracts in the two value-brackets included EADS (Europe), EDS, General Dynamics, Halliburton, Lockheed Martin, and Raytheon (all U.S.), Finmeccanica (Italy), and Thales Defense (France).

The outcome of the changes noted was consolidation throughout U.K. defense industry, on the one hand, and an increase in the role of foreign-owned companies on the other. While the overall effect has been to reduce the number of firms competing with each other, the extent of competition within subsectors of the industry (judged by number of firms) remains highly variable. MoD information on companies possessing what it calls Platform Systems Level Capability (PSLC) in the U.K. captures some of the differences. ${ }^{3}$ At one extreme, three subsectors are now dominated by a single player: BAE Systems has for many years been the single source of PSLC in the case of fast jet combat aircraft. Thanks to consolidation over the last decade or so, it now also occupies a similar position in relation to armored fighting vehicles. And only Marshall of Cambridge offers PSLC in the strategic airlift (C-130) subsector. At the other end of the spectrum, as many as 15 firms appear to offer PSLC in non-embedded C4ISTAR. Between the extremes, the remaining five sectors are populated by as few as two firms with PSLC (helicopters) and as many as five (complex surface warships and royal fleet auxiliary). 
The consequences of industry consolidation for innovation in the defense sector have attracted considerable academic and policy attention outside the U.K., especially in the United States. Some have argued that the main danger posed by mergers is that technological competition will decline and that any remaining supplier(s) will stand fast against new design approaches that may threaten their position. ${ }^{4}$ Others have observed that increased innovation in combat aircraft occurs at times of increased demand and the emergence of new component technologies and significant changes in military threat perceptions. Generally, larger numbers of experienced and credible prime contractors are more likely than lower numbers to promote the greater competition to innovate that leads to significant new technology development. In many cases, the key innovations that have led to radical change have come from firms who were not the dominant players at the time but members of a larger group surrounding them. ${ }^{5}$ In a study of competition and innovation in the U.S. fixed wing military aircraft industry, it has also been argued that there were potentially serious questions about the level of competition and that innovation in a future environment might be dominated by one or two credible prime contractors. ${ }^{6}$ Until now, there has been little or no academic discussion of the impact on industry level innovation of changes in the structure of the U.K. defense industry, and this is a gap to which we wish to draw attention. But the lack of data comparable to that available in the United States inevitably leads us to be more speculative than definitive in our analysis. In such cases, guidance from theory can be useful.

Industry competition and innovation: theory

Consolidation implies a reduction in the number of firms competing in an industry. As well as the number of firms currently active within it, however, the level of competition in an industry is affected by actual and perceived threats of potential entry. Furthermore, the relationship between the effect on competition of increasing or decreasing the number of firms may well be nonlinear: increasing the number from one (monopoly) to two (duopoly) may well yield a greater increase in competition than increasing the number from, say, five to six. Economists have often argued that when change of this kind occurs, the level and intensity of innovation effort may be affected. While the most commonly used measure of the level of competition is some version of the average price-cost margin within the industry (see the studies reported below), such information is impossible to construct for defense industry from the publicly available data. (And while many firms involved in defense contracts also supply civil markets, their published accounting data do not permit separation of the profits of one type of work from the other.) We therefore focus solely on the number of firms. We also follow the common practice in many economic studies of taking R\&D as an acceptable proxy for innovation activity. ${ }^{7}$

Stated succinctly, the theory linking innovation to competition rests on the operation of forces that work in opposite directions. On the one hand, a so-called
Schumpeter effect predicts that an increase in competition will whittle away profits that would otherwise have been available for investments in innovation. This implies a negative relationship between the level of competition and innovation. On the other hand, some scholars have argued that increasing competition prompts previously slack management teams now to invest more in innovation, with a view to avoiding the threat of takeover or bankruptcy by enhancing their firm's competitiveness. ${ }^{8}$ Taken at face value, the first effect suggests consolidation should yield increasing innovation and the second decreasing innovation. The theory offers little guidance on (1) the relative sizes of the opposing effects, (2) whether the relative sizes of the effects might vary with the initial level of competition, and (3) whether we should be entitled to assume symmetry in the size and duration of the effects when competition decreases as well as when it increases. Empirical attempts to resolve such issues also need to acknowledge the implications of an important additional theoretical claim: that the levels of competition and innovation in an industry are simultaneously codetermined by a deeper force, "technological opportunity," that varies in its impact from one sector to another. ${ }^{9}$ Technological opportunity is reflected in the (downward) responsiveness of production costs to a given percentage increase in innovation investment such as R\&D. Over a cross-section of industries with similar demand responsiveness to price (price elasticity), higher levels of technological opportunity are predicted to yield both greater concentration and more innovative activity. It is thus necessary to control for technological opportunity when seeking to identify the relationship between industry structure and competitiveness on the one hand and industry innovation on the other.

Focusing on industries of similar technological opportunity (and also facing similar price elasticities), the predictions of theory turn out to be ambiguous. A given variation in the level of competition could be associated with either higher or lower levels of innovation. From any given starting point, an increase in competition could occur alongside either an increase or decrease in innovation, depending on the relative strengths of the two forces described above. The same is also true of a decrease in competition. When the Schumpeter effect dominates, more (less) competition is associated with less (more) innovation. When the Schumpeter effect is relatively less important, more (less) competition is associated with more (less) innovation.

Industry competition and innovation: recent empirical evidence

The relationship between industry structure and innovation has been of longstanding interest to economists, and much empirical analysis has been undertaken to clarify the nature and strength of the links involved. As Nickell points out, however, almost all of the earlier work in the area can be regarded as unenlightening because it fails to control for industry-specific variations in technological opportunity. ${ }^{10}$ Studies that do allow for such variations come to opposite conclusions on the innovation impact of increasing competition. ${ }^{11}$ But more recently researchers have started to converge on 


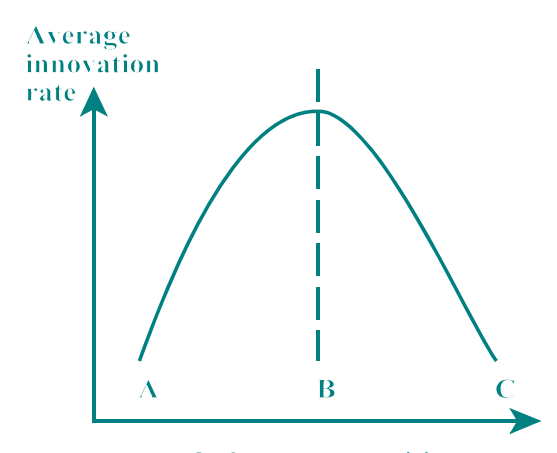

Industry competition

Figure 1: The inverted U-shape relationship between industry competition and innovation.

the finding that there is a nonlinear, inverted U-shape relationship between levels of competition and innovation. ${ }^{12}$ When the number of competitors in an industry increases from the lowest possible base of a single firm (monopoly), industry-wide innovation intensity at first rises and then declines again as competition increases further. Representing such findings schematically in Figure 1, the segment $A B$ is the range in which a positive relationship is found between industry competition and innovation, an increase (decrease) in one being associated with an increase (decrease) in the other. Along the segment BC, the relationship becomes negative, an increase (decrease) in one being associated with a decrease (increase) in the other.

If the theory we have outlined has explanatory power, then (controlling for technological opportunity and price elasticity) the inverted U-shape implies the Schumpeter effect dominates at low levels of competition but ceases to be dominant when the number of firms increases above a critical level. In their empirical work, Tingvall and Poldahl find the AB segment encompasses variations between monopoly and duopoly and possibly a three-firm oligopoly, with the peak of the inverted $\mathrm{U}$ occurring at a point between two and three firms in the industry.

We now turn to the innovation experience of the U.K. defense industry, taking $\mathrm{R} \& \mathrm{D}$ as a proxy, to discover how that has varied with the structural change discussed above.

\section{U.K. defense industry innovation}

Economic explanations for variations in business R\&D spending are most potent when it can be assumed that firms fund the investment themselves. Figure 2 compares changes in the value of defense R\&D conducted by industry with that conducted by government and universities. ${ }^{13}$ As may be seen, total real defense $R \& D$ spending has fallen sharply since the Cold War: by 2005 it was 40 percent lower than in 1989. Defense R\&D performed by industry now represents by far the largest share of defense R\&D conducted in the United Kingdom. Even before the formation of QinetiQ, industry performed around two-thirds of U.K. defense R\&D. The value of defense R\&D performed by industry fell dramatically, by 39.5 percent, between 1989

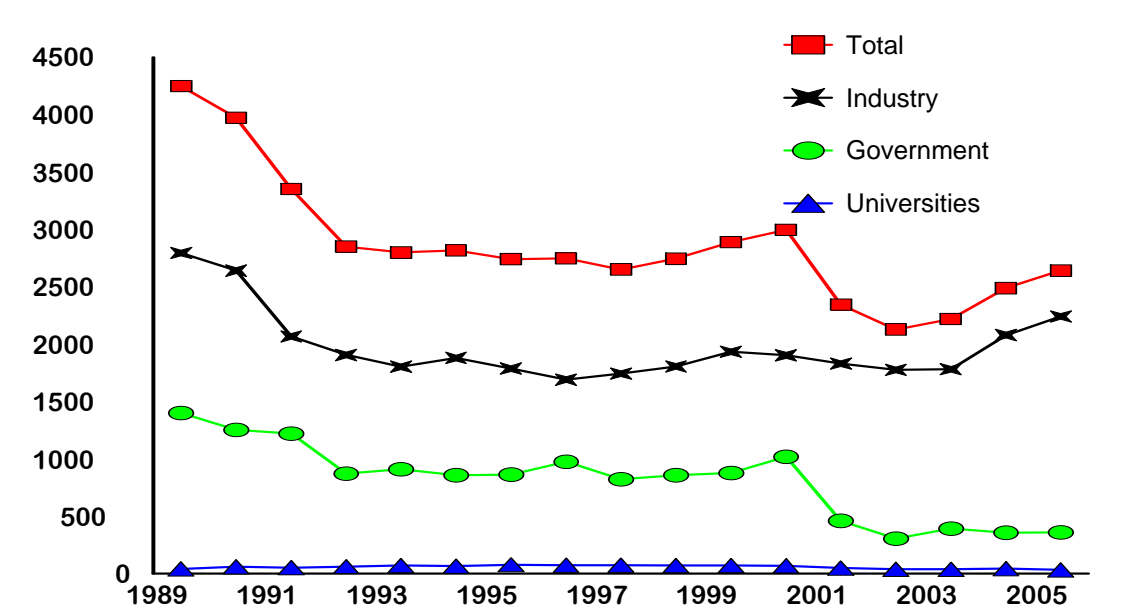

Figure 2: Defense R\&D conducted in the U.K., by performer, 1989-2005 ( $£ \mathrm{mn}$ in constant 2005 prices). Source: Office of National Statistics,

http://www.statistics.gov.uk/StatBase/tsdataset.asp?vlnk=584\&More=N\&All=Y.

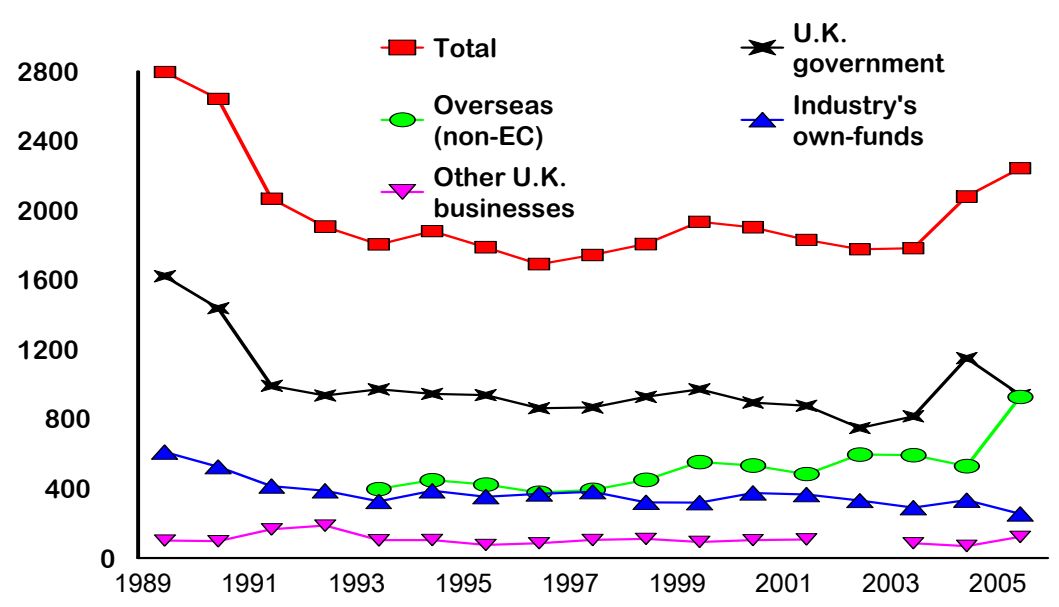

Figure 3: Sources of funds for defense R\&D in UK businesses, 1989-2005 ( $£$ mn in constant 2005 prices). Source: Office of National Statistics,

http://www.statistics.gov.uk/StatBase/tsdataset.asp?vlnk=571\&More=N\&All=Y

and 1996, the spending low-point. Despite an increase in later years, defense R\&D conducted by industry in 2005 was still almost 20 percent below its 1989 level.

Figure 3 shows changes in the sources of funds for defense R\&D in U.K. 
While the U.K. defense industry has been funding substantially less $R \& D$ from its own sources there has been a striking increase in the importance of funding from overseas.

businesses between 1989 and 2005 The figure reveals that industry's own-funded R\&D saw a remarkable decline, constituting an increasingly modest share of the defense $R \& D$ conducted by U.K. businesses. In 1989, industry's own-funded defense R\&D accounted for 20 percent of its R\&D, but by 2005 this had fallen to a little over 11 percent. In absolute terms, in 1989 the industry funded defense R\&D worth $£ 610$ million (in 2005 prices). By 2005 this had fallen to a little over $£ 250$ million. This represents a dramatic decline of almost 60 percent in real terms between 1989 and 2005. ${ }^{14}$

While the U.K. defense industry has been funding substantially less R\&D from its own sources there has been a striking increase in the importance of funding from overseas. Overseas sources of funding for defense R\&D conducted by U.K. companies has more than doubled since 1993 to reach $£ 927$ million in 2005 . In percentage terms, overseas sources have increased from 22 percent to 41 percent of funding of defense R\&D in U.K. businesses. (We speculate that this reflects the growing importance of international collaborative projects, particularly the Joint Strike Fighter, and increasing efforts by U.K. companies to obtain research contracts from foreign governments, particularly the United States. At the same time, U.K. government funding for defense R\&D conducted by U.K. businesses has declined.)

Discussion

The number of companies awarded major MoD contracts (as defined earlier) fell over our period of analysis from 16 to 13 . At the same time, industry own-funded R\&D fell sharply and overseas-funded R\&D rose. Are these observations connected?

Structural explanation

Taking the industry overall, the simultaneous fall in own-funded R\&D and rise in consolidation could be accounted for by arguing either that the Schumpeter effect was the only causal relationship at work or that it became increasingly dominant as competition declined. If the Schumpeter effect were the only one at work, we would have to conclude that the U.K. defense industry was an exceptional case that did not fit with the findings of the empirical studies suggesting the existence of an inverted U-shape relationship, which implies the operation of opposing forces. If both effects were at work, we would have to say that the peak of the inverted U occurred with a structure of at least 15 firms, which seems implausible and is very much at odds with the findings of Tingvall and Poldahl.

We believe, however, that it may not make sense to view the "defense industry," with all its diversity and heterogeneity, as a construct comparable with, say, "tire manufacture” or "electricity generation.” It may make more sense to disaggregate the industry into its component parts. ${ }^{15}$ We noted before that in three subsectors (fast jet combat aircraft and maritime patrol fixed wing; strategic airlift; armored fighting vehicles) conditions had become less competitive in our terms or, where there was monopoly to start with, no more competitive. There are also low numbers of competitors in helicopters (2) and submarines (3), and in the remaining sectors, two with 4, one with 5 and one (non-embedded C4ISTAR) with 15. Of these, helicopters and submarines had become no more competitive in terms of firms performing MoD work. But this is a mixed bag, and it is not impossible that some subsectors (in particular non-embedded C4ISTAR) may have become more competitive rather than less. $^{16}$

Clearly, it would be dangerous to put down observed changes in R\&D to changes in industry structure alone. But a possible explanation for the observed fall in own-funded R\&D comprises three parts. First, for subsectors starting out with a small number of competitors, consolidation took those elements of the overall industry down the AB segment of the inverted U-shape in Figure 1, leading to a reduction in $\mathrm{R} \& \mathrm{D}$ along with a reduction in competition. Second, for the remaining subsectors, competition either increased, decreased, or remained unchanged, with ambiguous outcomes for R\&D. And third, the overall impact on industry R\&D would be negative if (a) the effects of parts 1 and 2 were both negative or if (b) any positive effects of part 2 were outweighed by negative effects of part 1 . The previous paragraph indicates that five out of nine subsectors had three firms or fewer in 2005, and we know that consolidation played a major role in producing a monopoly in at least the case of armored fighting vehicles. One of the remaining four, non-embedded C4ISTAR clearly experienced new entry during the period which, given the relatively large number of players in the subsector, may have taken it down the BC segment of the inverted U-shape in Figure 1. We could not identify any cases in which a change in subsector player numbers might be expected to yield an increase in $R \& D$, given the operation of an inverted U-shape relationship. In such cases, initial one-firm or two-firm subsectors would have experienced a rise in the number of players, or initial many-player subsectors would have seen a modest fall in the number of firms. On the basis of these observations, we would argue that changes in the industry structure alone were more likely to suppress business innovation than encourage it.

We would not wish, however, to look to consolidation per se as the only explanation of declining own-funded R\&D. As Figure 3 indicates, at the same time as industry's own funds have declined as a proportion of the total, non-EC overseas sources of funding have increased. As stated before, between 1993 and 2005, these sources of funding for defense R\&D conducted by U.K. companies increased from 22 percent of the total to 41 percent. The Office of National Statistics (ONS) offers no further information on the exact source of these funds, but the rising inflow might have arisen from the increasing significance of international collaborative projects and 
the fruits of research contracts won with non-EC overseas governments.

Data are not available in the public domain to test these propositions further against the evidence but, in any case, we believe that other factors may well also have been at work. We refer to these as nonstructural explanations.

Nonstructural explanations

Three types of nonstructural explanation are considered here. First, total government demand for U.K. defense industry output has fallen. As in many other parts of the western world, military equipment spending declined in real terms between 1990 and 2000 in the United Kingdom, offering fewer opportunities and incentives for industry to invest in innovation. But this also looks like a partial explanation, at best, since MoD equipment spending fell by 21 percent while industry own-funded R\&D fell by an even larger proportion, 28 percent. Second, procurement reforms may also have had an effect. The so-called Levene defense procurement reforms of the 1980s led to a shift from cost-plus to fixed-price contracts with a view to reallocating program risk from the MoD to prime contractors. This may have had the effect of reducing business incentives to undertake high-risk technological innovation since contractors may seek to maximize profit (or minimize loss) under fixed-price contracts by cutting back on quality or adhering rigidly to specifications rather than experimenting with alternatives. Third, another sort of explanation for the relationship that we have observed may lie in the direction of causation flowing from innovation to industry structure rather than structure to innovation. We know that the cost, complexity, and risk of defense innovation have much increased in recent decades and this, in itself, may have contributed to consolidation. If large multidivisional and multiproduct defense companies are better positioned to spread the costs and risks of innovation, we may have been observing innovation driving consolidation in the U.K. defense industry. Many medium-sized companies concluded in the late 1980s and early 1990s that rising $R \& D$ costs and risks, along with shrinking market opportunities, meant that they should either exit through divestment or seek to grow through acquisition. Some chose to exit and were replaced by larger operators, often with international reach.

\section{Policy implications}

On the basis of the discussion in this article, we believe that U.K. defense industry policymakers have a number of policy options available to them. First, if further research were able to confirm the inverted U-shape relationship found in many other industry environments, policies aimed at increasing the number of competitors in one or two-player subsectors could stimulate an increase in industry innovation. MoD has already made the U.K. defense market contestable by threatening or actually opening up its national markets to competition from foreign firms. Equally, MoD might enhance competition through procurement reforms that make it easier for nondefense suppliers to act as prime contractors. For subsectors already well-populated with firms, however, such action could be counterproductive. At most, therefore, policymakers should consider influencing the industry structure (i.e., number of players) only in some circumstances. They would need to have better data than we have been able to access on the parameters of the inverted U-shape relationship or, better, about the relative strength of the forces shaping the relationship. And they would need to have a reasonable degree of confidence on the stability of the relationship. Given the defense industry environment globally, we also caution that increasing competition might reinforce incumbents in their belief that the U.K. is an unattractive market and cause them to redouble their efforts to shift the focus of their investments from the United Kingdom to the United States.

Second, to the extent that declining demand may have stifled innovation investments, increasing demand might restore the strength of incentives. But the potential for increased defense-related innovation should not be used as an argument for expanding defense equipment purchases. Increased defense spending or changes in its composition can only be justified logically in terms of changed strategic requirements. Third, if fixed-price contracts inhibit industry innovation, current efforts to introduce risk-sharing into defense contracts should assist, and MoD should persist, with further variations on the contractual incentives theme to uncover what achieves best results. Optimal contracts in this area appear more a matter of trial and error than prior knowledge. ${ }^{17}$

Fourth, policy should encompass the broader defense industry supply base. The U.K. MoD’s Defence Industrial Strategy (2005) and Defence Technology Strategy (2006) both recognize that procurement policies need to ensure that suppliers receive proper returns for innovation and that value flows through to the layers of the supply chain that are innovating rather than being retained by prime contractors.

\section{Conclusion}

We have speculated in this article that structural issues, found to be relevant to explaining industry innovation generally, may also have played a part in U.K. defense industry. Given the constraints on publicly available data, however, we cannot at this stage take the argument further and readily concede that other factors such as demand and contractual incentives need to be taken into consideration. Future research might also seek to obtain better measures of competitive pressure (related to price-cost margins) and of innovation. Our analysis has been based on an input measure of innovation (defense R\&D spending) and it would be desirable to develop suitable output measures. A starting point could be a time-series analysis of patenting data for U.K. defense companies. There is also a need for case studies of defense equipment innovation in the U.K. as a means of understanding the dynamics of the innovation process and the relative importance of competition, industry $R \& D$, government conducted R\&D, and linkages with overseas sources of technology. 


\section{Notes}

Peter Hall is Emeritus Professor in the School of Business, University of New South Wales at the Australian Defense Force Academy, Canberra, ACT, Australia. He may be reached at p.hall@adfa.edu.au. Andrew James is Senior Lecturer at the Manchester Business School, University of Manchester, Oxford Road, Manchester, M13 9PL, U.K. He may be reached at andrew.james@mbs.ac.uk. The research assistance of Chris Redpath is gratefully acknowledged.

\section{See Aghion, et al. (2005); Tingvall and Poldahl (2006).}

2. U.K. Defence Statistics (1991; 2006).

\section{MoD (2005).}

4. See Kovacic and Smallwood (1994).

5. See Lorell (2003).

6. Birkler, et al. (2003).

7. We fully accept that R\&D as an input measure for innovation is an incomplete and imperfect metric for innovation performance more generally. That said, aerospace and defense, together with pharmaceuticals, account for over half of the R\&D performed by the U.K.'s top 750 companies (Harris, Nightingale, and Acha, 2006, p. 20), suggesting that R\&D may be more important as a driver of innovation in defense than in many other sectors of industry.

8. For example, Scherer (1967) and Hart (1983).

9. Dasgupta and Stiglitz (1980).

\section{Nickell (1996).}

11. For example, Geroski (1990); Nickell, (1996).

12. Aghion, et al. (2005); Tingvall and Poldahl (2006).

13. Universities conduct only a modest amount of defense R\&D in the U.K. and are not considered here. On the role of British universities in defense work, see Langley (2008).
14. To clarify, Fig. 2 shows how all of the defense R\&D conducted in the U.K. is divided up among the various performers of the R\&D. The "total" shown in Fig. 2 is thus the result of adding together the R\&D done in any given year by all of the defense R\&D performers. R\&D performed by industry in 1989 (at 2005 prices) was 2,795 million pounds, within an overall total of R\&D performed of 4,248 million pounds. Fig. 3 relates only to defense R\&D carried out in U.K. business and shows the sources of funds for that R\&D work. The "total" shown in Fig. 3 is thus the result of adding together the amounts of funds from all sources of funding for U.K. business defense R\&D and is the same (actually, 2,796 million rather than 2,795) as the amount shown in Fig. 2 as the amount spent by industry on defense R\&D. In brief, "total" in the two figures means different things, but everything adds up.

15. Kovacic and Smallwood (1994) do something similar in their analysis of competitiveness in U.S. defense industry.

16. The picture is complicated by the fact that subsectors can be defined in different ways. Whichever way subsector boundaries are drawn, it remains quite possible for competition to have decreased in some cases and increased in others and to yield the same overall result.

17. Rogerson (1995).

\section{References}

Aghion, P., N. Bloom, R. Blundell, R. Griffith, and P. Howitt. 2005. "Competition and Innovation: An Inverted-U Relationship." The Quarterly Journal of Economics, Vol. 120, No. 2, pp. 701-728.

Birkler, J., A. Bower, J. Drezner, G. Lee, M. Lorell, G. Smith, F. Timson, W. Trimble, and O. Younossi. 2003. Competition and Innovation in the U.S. Fixed-Wing Military Aircraft Industry. Santa Monica, CA: RAND.

Dasgupta, P. and J.E. Stiglitz. 1980. "Industrial Structure and the Nature of Innovative Activity.” The Economic Journal, Vol. 90, No. 358, pp. 266-293.

Geroski, P.A. 1990. “Innovation, Technological Opportunity and Market Structure.” Oxford Economic Papers, Vol. 42, pp. 586-602.

Harris, M., P. Nightingale, and V. Acha. 2006. The Innovation Gap: Why Policy Needs to Reflect the Reality of Innovation in the UK. London, NESTA (National Endowment for Science, Technology and the Arts).

Hart, O. 1983. “The Market Mechanism as an Incentive Scheme.” Bell Journal of Economics, Vol. 14. No. 2, pp. 366-382.

Kovacic, W.E. and D.E. Smallwood. 1994. "Competition Policy, Rivalries, and Defense Industry.” Journal of Economic Perspectives, Vol. 8, No. 4, pp. 91-110. Langley, Chris. 2008. "Universities, the military, and the means of destruction in the 
United Kingdom.” Economics of Peace and Security Journal, Vol. 3, No. 1, pp. 49-55.

Lorell, M. 2003. The U.S. Combat Aircraft Industry, 1909-2000. Santa Monica, CA: RAND.

[MoD] Ministry of Defence. 1991. UK Defence Statistics 1991. London: Ministry of Defence.

[MoD] Ministry of Defence. 2005. Defence Industrial Strategy. London: Ministry of Defence.

[MoD] Ministry of Defence. 2006. Defence Technology Strategy. London: Ministry of Defence.

[MoD] Ministry of Defence. 2006. UK Defence Statistics 2006. London: Ministry of Defence.

Nickell, S. 1996. “Competition and Corporate Performance.” Journal of Political Economy, Vol. 104, No. 4, pp. 724-746.

Rogerson, W.P. 1995. "Incentive Models of the Defense Procurement Process." Chapter 12 in K. Hartley and T. Sandler, eds. Handbook of Defense Economics, Vol. 1. Amsterdam: Elsevier.

Scherer, F.M. 1967. "Market Structure and the Employment of Scientists and Engineers.” American Economic Review, Vol. 57, pp. 524-531.

Tingvall, P.G. and A. Poldahl. 2006. "Is There Really an Inverted U-shape Relation Between Competition and Innovation?” Economics of Innovation and New Technology, Vol. 15, No. 2, pp. 101-118. 